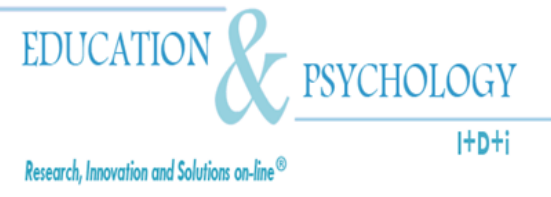

\title{
Orientación integral en los centros educativos y en el aula
}

\author{
Denyz Luz Molina Contreras y Catherina De Luca
}

Universidad Nacional Experimental de los Llanos Ezequiel Zamora, Caracas

\section{Venezuela}

Correspondencia: Denyz Luz Molina Contreras. Dirección postal: 5201. Venezuela.

E-mail: opeiunellez@gmail.com

(C) Education y Psychology $\mathrm{I}+\mathrm{D}+\mathrm{I}$ and Editorial EOS (Spain) 


\section{Resumen}

El estudio acerca de la concepción de Orientación Integral en los Centros Escolares y el Aula, lleva a realizar una revisión de algunas definiciones de la orientación educativa que se manejan en los últimos años, con el fin de verificar el concepto que se promueve en la educación formal y en la práctica pedagógica diaria, así como su correspondencia con las políticas educativas que se promueven, con el fin de configurar algunas estrategias de formación permanente dirigidas a los agentes educativos corresponsables directos de la orientación de los escolares. Se presenta una aproximación al concepto de orientación integral y se perfilan algunas estrategias de orientación que se están promoviendo actualmente en los centros escolares con fines de prevención, desarrollo, intervención social y atención a la diversidad.

Palabras Clave: orientación integral, centro educativo, estrategias de orientación, orientación educativa

Recibido: 08/01/09 Aceptación inicial: 08/01/09 Aceptación final: 11/02/09 


\title{
Comprehensive guidance at schools and in the classroom
}

\begin{abstract}
The study on the design of comprehensive guidance in schools and the classroom, leads to a review of some definition of educational guidance are handled in recent years in order to verify the concept promoted in education formal and correspondence with educational policies, in order to set up some training strategies aimed at the direct-responsible educational agents targeting schoolchildren. It gives an approximation of the concept of educational counseling and guidance outlined some strategies that are currently being promoted in schools.
\end{abstract}

Keywords: comprehensive guidance, school, counseling strategies, guidance

Received: 01/08/09 Initial Acceptance: 01/08/09 Final Acceptance: 02/11/09 


\section{Introducción}

Este estudio se deriva de una pormenorizada revisión de los constructos acerca del desarrollo integral de la persona, como una de las esenciales aspiraciones de todos los sistemas educativos iberoamericanos y del mundo en general y no puede ser vista de otra manera, si aspiramos a que la educación contribuya realmente a la formación de individuos útiles, así mismos y a la sociedad.

La preocupación por la inclusión, atención a la diversidad, intervención social, y pertinencia de las políticas educativas persisten aun en la gran mayoría de los sistemas educativos, sin alcanzar mayor incidencia en la totalidad de la población escolar. En este contexto, una de las líneas de la gerencia educativa que mayor relevancia en teoría le otorga el sistema educativo es a la definición de estrategias para el desarrollo integral de la persona, desde la puesta en práctica de una concepción de orientación integral que implique la intervención fundamental de la familia, la escuela, la comunidad y las instituciones en general.

Sin embargo, es tan compleja la definición de la orientación integral, como su transferencia a la práctica formativa, la búsqueda de la misma se considera una utopía. En esta línea Robin (1972) defiende la perspectiva de una educación integral que se basa en el derecho, independientemente de sus condiciones sociales; de desenvolver tanto como sea posible, sus facultades sociales; de desenvolver tanto como sea posible, sus facultades físicas, intelectuales y morales. Así define sus perspectivas (p.2):

"...No tenemos la más remota pretensión de hacer de nuestros alumnos sabios universales..."

El nombre de la educación integral se lo designamos a la educación que tiende al desenvolvimiento progresivo y bien equilibrado de todo el ser, sin lagunas ni mutilaciones, sin descuidar en ningún aspecto la naturaleza humana, ni sacrificarlo en detrimento de otros. Tanto en el conjunto de la educación, como en una de sus partes consideradas separadamente, tenemos que aplicar el mismo principio de integridad, de entereza -si preferimos esta bella palabra que merece ser rejuvenecida- de proporción, de armonía, persuadidos de que de esto depende la felicidad del propio individuo y su adaptación para colaborar con la construcción de la felicidad de todos". 
Una de las más lamentables anomalías que puede resultar de la reducción de este concepto es, cuando el ser humano vive un proceso de masificación y despersonalización, pérdida de identidad y abandono del propio yo, lo que lo conduce a vivir un profundo deterioro de su ser como persona disminuyendo en un alto grado la responsabilidad y el protagonismo personal que está llamado a desempeñar.

La verdadera educación integral es aquella que se propone como objetivo la formación de la persona humana en orden a su fin último, que es la búsqueda de la verdad, la libertad y el bien de las sociedades de las que el hombre es miembro y en cuyas responsabilidades participará cuando llegue a ser adulto.

Desde la perspectiva de la orientación y formación integral, Zavala, Valadez, y Vargas (2008) plantean la inteligencia emocional como un constructo que recoge tanto habilidades sociales como habilidades emocionales que una vez que la persona las integra así mismo, constituyen el soporte fundamental para el abordaje de los procesos de socialización y realización personal.

Interpretando a Augusto, Aguilar y Salguero (2008) las actitudes bien sean positivas o negativas influyen en el desenvolvimiento de la persona, es decir una persona optimista tiende a logar las metas con mayor efectividad, que aquellos que son pesimistas.

Ambas investigaciones consideran la inteligencia emocional como una teoría que explica la importancia que tienen las habilidades sociales y emocionales en la socialización, e integración social de la persona, fundamento que se considera al momento de configurar una aproximación a la definición de la Orientación Integral

\section{Concepción teórica de la Orientación Educativa vs Orientación Integral}

Desde el ámbito de la orientación educativa se han realizado grandes esfuerzos por crear un cuerpo teórico y metodológico organizado que facilite en el proceso formativo la prevención, desarrollo, intervención y atención a la diversidad tanto del escolar como de los agentes educativos en su contexto inmediato, así como por construir un cuerpo teórico acerca de la Orientación Integral en los centros escolar. A partir del surgimiento de la orientación, diversos autores se han encontrado con la dificultad para definirla en función de sus objetivos y campos de acción. Son muchas las definiciones surgidas a lo largo del siglo XX y de lo que va del siglo XXI que abarcan una amplia gama de perspectivas a las cuales no ha estado ligada siempre la educación y, por ende la función docente. 
De acuerdo con Martínez de Codès (1998), el concepto de orientación, sus funciones y el modo de planificarla fueron, desde el comienzo, imprecisos, problemáticos y, con frecuencia, contradictorios. Según este, autor, la orientación ha sido tratada desde diversos enfoques: como proceso que ayuda a la persona a tomar decisiones vocacionales, como forma de asesorar al individuo para la resolución de problemas personales y/o sociales, como sistema o modelo de intervención que brinda asistencia al sujeto, y, más recientemente, como eje transversal del currículo, presente en los actos que emprende el docente en el contexto escolar y extraescolar.

Dada la complejidad de este término, la comprensión del mismo exige recurrir a una diversidad de fuentes y perspectivas que ayuden a buscar la aproximación a su definición. Por ello, en el cuadro 1, realizamos una revisión de las definiciones que presentan elementos que nos llevan a configurar una visión de la concepción de Orientación Integral, las mismas han servido de referencia para establecer su comparación con la práctica orientadora en los centros escolares y el aula.

Cuadro 1. Definiciones que presentan una visión integrada de la orientación

\begin{tabular}{|c|c|c|}
\hline DEFINICIÓN & OBJETIVOS & FUNCIONES \\
\hline $\begin{array}{l}\text { Proceso dirigido a la atención del individuo } \\
\text { como una unidad estableciendo varios } \\
\text { campos: la orientación personal-social, } \\
\text { escolar, vocacional y/o profesional } \\
\text { (Valcárcel,1990) }\end{array}$ & $\begin{array}{l}\text { - Desarrollar personal- } \\
\text { social, vocacional y/o } \\
\text { profesional }\end{array}$ & $\begin{array}{l}\text { - Desarrollo de habilidades } \\
\text { personales y profesionales }\end{array}$ \\
\hline $\begin{array}{l}\text { Proceso dirigido a la ayuda del individuo } \\
\text { en las diferentes áreas de desarrollo } \\
\text { (Millán, 1990) }\end{array}$ & $\begin{array}{l}\text { - Ayudar al desarrollo } \\
\text { de las diferentes áreas }\end{array}$ & Desarrollo integral. \\
\hline $\begin{array}{l}\text { Proceso centrado en el acto pedagógico con } \\
\text { carácter de diagnóstico y ecológico cuyo } \\
\text { fin va dirigido al desarrollo del sujeto (Re- } \\
\text { petto, 2000) }\end{array}$ & $\begin{array}{l}\text { - Promover el desarrollo } \\
\text { del sujeto }\end{array}$ & $\begin{array}{l}\text { - Diagnóstico } \\
\text { - Desarrollo }\end{array}$ \\
\hline $\begin{array}{l}\text { Proceso integrado al currículo con énfasis } \\
\text { en los principios de prevención, desarrollo } \\
\text { y atención a la diversidad en las áreas afec- } \\
\text { tiva, emocional escolar y vocacional (M. E. } \\
\text { Diseño curricular, 1997) }\end{array}$ & $\begin{array}{l}\text { - Facilitar la Prevención } \\
\text { y el desarrollo }\end{array}$ & $\begin{array}{l}\text { - Prevención } \\
\text { - Desarrollo } \\
\text { - Diversidad }\end{array}$ \\
\hline $\begin{array}{l}\text { Proceso íntimamente relacionado con el } \\
\text { acto educativo, tiene carácter procesal y } \\
\text { ordenado al desarrollo integral del indivi- } \\
\text { duo (Martínez, 1998) }\end{array}$ & $\begin{array}{l}\text { - Guiar el desarrollo } \\
\text { integral del individuo }\end{array}$ & $\begin{array}{l}\text { - Prevención } \\
\text { - Desarrollo }\end{array}$ \\
\hline $\begin{array}{l}\text { Suma total de experiencias dirigidas al } \\
\text { logro del máximo desarrollo del sujeto } \\
\text { (Álvarez et al.,1998) }\end{array}$ & $\begin{array}{l}\text { - Promover el desarrollo } \\
\text { del individuo }\end{array}$ & $\begin{array}{l}\text { - Prevención } \\
\text { - Desarrollo }\end{array}$ \\
\hline
\end{tabular}




\begin{tabular}{|c|c|c|}
\hline $\begin{array}{l}\text { Proceso de ayuda continua a todas las per- } \\
\text { sonas, en todos sus aspectos, con objeto de } \\
\text { potenciar el desarrollo humano a lo largo } \\
\text { de toda la vida(Álvarez y Bisquerra, 1996) }\end{array}$ & $\begin{array}{l}\text { - Atención a las áreas de } \\
\text { desarrollo } \\
\text { - Potenciar el desarrollo } \\
\text { integral del individuo }\end{array}$ & $\begin{array}{ll}\text { - } & \text { Prevención } \\
\text { - } & \text { Desarrollo } \\
\text { - } & \text { Intervención social }\end{array}$ \\
\hline $\begin{array}{l}\text { Conjunto de conocimientos metodológicos } \\
\text { y principios teóricos que fundamentan la } \\
\text { planificación, diseño, aplicación y evalua- } \\
\text { ción de la intervención psicopedagógica } \\
\text { (Vélaz de M., 1998) }\end{array}$ & $\begin{array}{l}\text { - Prevención y desarro- } \\
\text { llo }\end{array}$ & $\begin{array}{l}\text { - Intervención } \\
\text { - Prevención } \\
\text { - Desarrollo }\end{array}$ \\
\hline $\begin{array}{l}\text { Proceso preventivo y de desarrollo del } \\
\text { individuo (Boronat, 1999) }\end{array}$ & $\begin{array}{l}\text { - Orientar el desarrollo } \\
\text { del individuo }\end{array}$ & $\begin{array}{l}\text { - Prevención } \\
\text { - Desarrollo }\end{array}$ \\
\hline $\begin{array}{l}\text { Proceso de prevención, desarrollo y aten- } \\
\text { ción a la diversidad del alumno con la } \\
\text { intervención de los agentes educativos } \\
\text { (Molina, 2001) }\end{array}$ & \begin{tabular}{|l|} 
- Prevención y desarro- \\
llo \\
- Conducir la interven- \\
ción de los agentes \\
educativos
\end{tabular} & $\begin{array}{l}\text { - Prevención } \\
\text { - Desarrollo }\end{array}$ \\
\hline $\begin{array}{l}\text { Proceso integrado al acto formador invo- } \\
\text { lucrando al alumno, los agentes educati- } \\
\text { vos, la comunidad y su contexto social(De } \\
\text { Luca, 2007) }\end{array}$ & \begin{tabular}{|l} 
- Desarrollo integral \\
- Intervención en el \\
contexto escolar \\
- Valoración de los \\
agentes educativos \\
\end{tabular} & $\begin{array}{ll}\text { - } & \text { Prevención } \\
\text { - } & \text { Desarrollo } \\
\text { - } & \text { Intervención } \\
\text { - } & \text { Valoración }\end{array}$ \\
\hline $\begin{array}{l}\text { La Orientación Educativa es un conjunto } \\
\text { de actividades dirigidas a los alumnos, } \\
\text { padres y profesores para ayudarles en el } \\
\text { desarrollo de sus tareas dentro del ámbito } \\
\text { específico de los centros escolares.(MEC, } \\
\text { 2008) }\end{array}$ & $\begin{array}{l}\text { - Ayuda } \\
\text { - Desarrollo de tareas } \\
\text { - Intervención en los } \\
\text { centros escolares }\end{array}$ & $\begin{array}{l}\text { - Intervención en los cen- } \\
\text { tros escolares }\end{array}$ \\
\hline $\begin{array}{l}\text { La orientación es el resultado de la acción } \\
\text { de apoyo permanente y mancomunado de } \\
\text { padres, madres, representantes, docentes y } \\
\text { comunidad escolar en general hacia los } \\
\text { escolares, con el fin de que se realice ple- } \\
\text { namente y sea útil a la sociedad(Molina, } \\
\text { 2009) }\end{array}$ & $\begin{array}{l}\text { - Acción permanente } \\
\text { - Red mancomunada } \\
\text { de apoyo } \\
\text { - Integración de agen- } \\
\text { tes educativos } \\
\text { - Realización personal } \\
\text { - Intervención social }\end{array}$ & $\begin{array}{ll}\text { - } & \text { Apoyar } \\
\text { - } & \text { Informar } \\
\text { - } & \text { Orientar } \\
\text { - } & \text { Ayudar } \\
\text { - } & \text { Integrar } \\
\text { - } & \text { Intervenir }\end{array}$ \\
\hline
\end{tabular}

\section{Evolución de la concepción de Orientación: aproximación a la integralidad}

A la luz de los conceptos que sobre la orientación se han manejado, se puede afirmar que a lo largo del presente siglo, pero sobre todo durante las tres últimas décadas, la orientación ha evolucionado desde un modelo clínico, centrado en el sujeto y menos atento a las circunstancias, hacia un modelo psicopedagógico, en el cual se implica toda la comunidad educativa (padres, familia, profesores, alumnos) hasta llegar a un modelo socio-psicopedagógico en el que también ha de estar presente la sociedad, unas veces como "sujeto-objeto" de orientación, y otras como facilitadora de la misma, aportando los medios para que los agentes puedan asumir su rol con mayor garantía.

Así, la orientación ha evolucionado desde una actividad básicamente diagnóstica y de carácter puntual a un enfoque más amplio, rico y comprensivo, procesual y diferencial, tomando en consideración las distintas etapas y tareas de desarrollo del individuo. De una orien- 
tación de tipo remedial como respuesta a las demandas sociales de la época, a una de tipo preventivo, destinada a influir sobre contextos sociales más amplios y a facilitar el desarrollo integral de la persona. De unos orígenes extraescolares y de carácter no educativo, a identificarse con la educación misma al considerarla como un proceso integrado al currículo.

\section{Concepción práctica de la Orientación Integral}

El planteamiento es asumir desde la participación de los padres, familia, docentes y comunidad en general la orientación del escolar como un todo. La intervención debe partir desde la concepción y a lo largo de toda la vida de la persona. No puede seguir siendo un momento fortuito, en determinadas circunstancias, solo para atender problemas o necesidades que emergen en la dinámica diaria. De allí que se trata en el estudio de comprender el concepto de orientación integral que se esta abordando en los centros escolares, y su relación con la práctica diaria. Tal como se refleja en el Cuadro 2.

\section{Cuadro 2. Resumen de investigaciones realizadas en los centros escolares y el aula}

\begin{tabular}{|c|c|c|c|}
\hline Autor & $\begin{array}{c}\text { Objetivos } \\
\text { de la investigación }\end{array}$ & Resultados & $\begin{array}{l}\text { Tensión entre teoría y práctica de } \\
\text { la orientación }\end{array}$ \\
\hline - Herrera, M(2006) & $\begin{array}{l}\text { - Rol del docente } \\
\text { como orientador }\end{array}$ & $\begin{array}{l}\text { - El } 80 \% \text { de los docentes } \\
\text { que participaron en la } \\
\text { muestra integrada por } 30 \\
\text { educadores expresaron } \\
\text { que el rol de orientador lo } \\
\text { asumen cuando el alumno } \\
\text { presenta problemas en el } \\
\text { área escolar, como el bajo } \\
\text { rendimiento, las inasisten- } \\
\text { cias. }\end{array}$ & $\begin{array}{l}\text { - La orientación en el Currículo se } \\
\text { concibe como un proceso inte- } \\
\text { grado al acto formativo, sin em- } \\
\text { bargo, la docente continua asu- } \\
\text { miendo la orientación como un } \\
\text { rol dirigido a la atención del es- } \\
\text { colar con problemas de rendi- } \\
\text { miento. }\end{array}$ \\
\hline - Molina, C (2008) & $\begin{array}{l}\text { - Analizar las estra- } \\
\text { tegias de orienta- } \\
\text { ción integral que } \\
\text { promueve el do- } \\
\text { cente }\end{array}$ & $\begin{array}{l}\text { - Las estrategias que el do- } \\
\text { cente con frecuencia utili- } \\
\text { za para promover la orien- } \\
\text { tación son: charlas, reu- } \\
\text { niones, encuentros, entre- } \\
\text { vistas con los padres. }\end{array}$ & $\begin{array}{l}\text { - Se asume fundamentalmente las } \\
\text { estrategias como acciones grupa- } \\
\text { les dirigidas al manejo de infor- } \\
\text { mación general inherente a la } \\
\text { dinámica escolar, sin embargo se } \\
\text { le da escaso tratamiento a la } \\
\text { orientación personal, con énfasis } \\
\text { en el desarrollo del autoconcepto. }\end{array}$ \\
\hline - De Luca, C (2007) & $\begin{array}{l}\text { - Autoestima del } \\
\text { escolar }\end{array}$ & $\begin{array}{l}\text { - Consideramos que el cen- } \\
\text { tro de la atención en la es- } \\
\text { cuela esta centrada en el } \\
\text { dominio de contenidos, } \\
\text { mas que en el desarrollo } \\
\text { del concepto de si mismo } \\
\text { del escolar }\end{array}$ & $\begin{array}{l}\text { - El logro de los objetivos de ense- } \\
\text { ñanza esta en proporción directa } \\
\text { con el desarrollo de los conteni- } \\
\text { dos, con escasa importancia en el } \\
\text { desarrollo de la autoestima. }\end{array}$ \\
\hline - Araque, C(2008) & $\begin{array}{l}\text { Práctica de la orien- } \\
\text { tación integral en } \\
\text { los centros escola- } \\
\text { res de educación } \\
\text { diversificada en } \\
\text { Venezuela }\end{array}$ & $\begin{array}{l}\text { La práctica de la orientación } \\
\text { esta sesgada hacia una deter- } \\
\text { minada área de atención del } \\
\text { escolar y dirigida hacia ámbi- } \\
\text { tos específicos que incluye el } \\
\text { aula, la escuela o la comuni- } \\
\text { dad, "escasas veces" se ma- } \\
\text { neja un enfoque integrado de } \\
\text { la orientación. }\end{array}$ & $\begin{array}{l}\text { - La práctica de la orientación } \\
\text { integral es un proceso complejo } \\
\text { y difícil de operacionalizar en la } \\
\text { práctica pedagógica diaria, nos } \\
\text { encontramos que la atención se } \\
\text { da en una determinada área de } \\
\text { desarrollo del escolar. }\end{array}$ \\
\hline
\end{tabular}




\begin{tabular}{|c|c|c|c|}
\hline $\begin{array}{l}\text { Vilera de Girón, A. } \\
(2000) \text {. }\end{array}$ & $\begin{array}{l}\text { «La deconstrucción } \\
\text { de la visión de } \\
\text { Ayuda. Otra mirada } \\
\text { de la Orientación». }\end{array}$ & $\begin{array}{l}\text { La práctica orientadora siem- } \\
\text { pre ha estado basada en un } \\
\text { modelo euro-centrista, cen- } \\
\text { trada en la llamada relación } \\
\text { de ayuda. Esa relación de } \\
\text { ayuda se corresponde en } \\
\text { modos de pensar a priori, es } \\
\text { decir, modos dependientes de } \\
\text { una visión utópica de perso- } \\
\text { nalidad auto-centrada y } \\
\text { además articulada con pará- } \\
\text { metros psicologizantes inscri- } \\
\text { tos en una cierta idea de suje- } \\
\text { to, de persona, del «deber } \\
\text { ser» de la razón-conciencia. } \\
\text { Esa relación de ayuda estuvo } \\
\text { dirigida a moldear la persona- } \\
\text { lidad. }\end{array}$ & $\begin{array}{l}\text { - Relación de ayuda centrada en la } \\
\text { persona, con parámetros psicolo- } \\
\text { gizantes. }\end{array}$ \\
\hline
\end{tabular}

\section{Conclusiones}

Del análisis de la concepción teórica que hemos manejado sobre la orientación integral se concluye que la mayoría de los autores expertos en el área han realizado esfuerzos por aproximarse a una concepción que integre los elementos que definen el ser humano como un todo integrado en sus partes, sin embargo también se reconoce que la operacionalización de esta concepción resulta con frecuencia compleja y difícil de llevar a la práctica formativa, aun cuando se realizan todas las acciones y se definan las estrategias de intervención más adecuadas y pertinentes, siempre se termina por asumir la ayuda en una determinada área del desarrollo o en especiales momentos de la vida del ser humano.

Desde el punto de vista de la operacionalización de la concepción de orientación integral, se centra en señalar que el concepto que ha plasmado el sistema educativo de cada país, ha tenido puntos coincidentes en su filosofía: procurar la atención integral del escolar, discrepantes en su praxologia. Sin embargo, este concepto ha estado plagado por políticas, significados y prácticas al interior de cada país, región, comunidad o centro escolar, que aproximan o distorsionan el concepto de integralidad del proceso orientador.

La concepción que maneja el profesorado con respecto a la Orientación Integral, esta centrada en ver la misma como La Orientación se concibe como el conjunto de estrategias y acciones grupales dirigidas al manejo de información general inherente a la dinámica 
escolar, con escaso tratamiento a la orientación personal. En algunos centros escolares la orientación es asumida como hora de encuentro con los estudiantes, también se le denomina hora de "guiatura", de resolución de conflictos, u otra denominación que ilustra solo un espacio dentro de la programación escolares para la atención a los problemas de los estudiantes, especialmente "problemas de rendimiento escolar", indisciplina o incumplimiento de normas institucionales. Frente a ello cabe preguntarse: ¿Cómo se asume la Orientación Integral”, para algunos profesores no existe tal orientación integral, solo la ilusión y la intención de aproximarse con nuestros actos a esa tan anhelada acción, la búsqueda de la felicidad suprema del ser humano.

La Orientación Educativa esta centrada fundamentalmente en la relación que se establece durante las actividades escolares, con énfasis en el desarrollo de los contenidos. Al docente se le asigna la actividad de orientación permanente, sin embargo, los resultados indican que su accionar como profesional integral esta centrado en la docencia.

En cuanto al concepto de orientación educativa que manejan los alumnos y agentes educativos, se precisa que existen tendencias antagónicas entre los que conciben la orientación como proceso dirigido a la resolución y atención a la persona con problemas y los que consideran la orientación como un proceso integrado al acto de enseñar y aprender. Tendencias que se ven ilustradas en los siguientes discursos tanto de padres como de alumnos y docentes: “la maestra de mi hijo, me expresa que el niño tiene bajo rendimiento en matemática, por lo que me sugiere un especialista en psicopedagogía o un orientador para que lo ayude en su problema?" de allí se deriva que el problema del niño debe ser tratado fuera del aula o en condiciones especiales, denotando un enfoque centrado en el problema, más no en la prevención y, el desarrollo e intervención social durante el acto de acción formativa. 


\section{Referencias}

Álvarez, M. (1998). Orientación educativa y acción orientadora. Relaciones entre la Teoría y la Práctica. Barcelona: CEDESC.

Álvarez, M. y Bisquerra, R. (1996). Modelos teóricos. Carácter multidisciplinar de la orientación. Orientación e Intervención Psicopedagógica. Manual de Orientación y Tutoría. Barcelona: Praxis.

Araque, C. (2008). Práctica de la Orientación Integral en los Centros Escolares de Educación Diversificada. Trabajo de Investigación no publicado. Universidad de Córdoba.

Augusto, J.M, Aguilar, Ma C., y Salguero, Ma. F. (2008). El papel de la IEP y del Optimismo/Pesimismo disposicional: En la resolución de problemas sociales: un estudio con alumnos de trabajo social. Electronic Journal of Educational Psychology, 15, 6(2), 363-382.

Bisquerra, R. y Álvarez González, M. (1998).Concepto de Orientación e Intervención Psicopedagógica. En R. Bisquerra (Cood.) Modelos de Orientación e Intervención Psicopedagógica, págs. 9-22). Barcelona: Praxis. S.A.

Boronat, J. (1999). Enfoque interdisciplinar en la formación del profesorado sobre los temas transversales. En asociación Española de Orientación y Psicopedagógica (Comp.) La orientación Educativa y la Intervención Psicopedagógica Integrada al Currículo. Valencia: AEOP.

De Luca, C. (2007). Autoestima del escolar. Trabajo de Investigación no publicado. Venezuela: Universidad de los Llanos Occidentales "Ezequiel Zamora"

Herrera, M. (2006). Rol del Docente como Orientador. Tesis de Grado no publicada, Universidad de los Llanos Occidentales "Ezequiel Zamora”, Venezuela

Martínez de Codès. (1997). La Orientación Escolar. Madrid: Sáenz y Torres.

Millan, A. (1990). Hacia una orientación integral. Madrid: Magisterio Español

Molina, D. (2008). Estrategias de Orientación Integral que Promueve el Docente. Trabajo de investigación no publicado, Universidad de los Llanos Occidentales "Ezequiel Zamora”. Venezuela.

Repetto, E. (2000). Tareas y Formación de los Orientadores en la Unión Europea. Madrid: UNED.

Robin, P (1972) Los grandes socialistas y la educación". Madrid: Fragua

Valcarcel, J (1990). Orientación Profesional y Promoción Humana. Madrid: Narcea, S.A 
Vélaz de Medrano. (1998). Orientación e Intervención Psicopedagógica. Conceptos, Modelos, Programas y Evaluación. Málaga: Aljibe.

Vilera de Girón, A (2000) La deconstrucción de la visión de ayuda otra mirada de la orientación. España

Vilera de Girón, A. (2000). La deconstrucción de la visión de Ayuda. Otra mirada de la Orientación. Revista Electrónica: http://www.geocities.com

Zavala, M. A., Valadez, Ma D., y Vargas, Ma C. (2008) Inteligencia emocional y habilidades sociales en adolescentes con alta aceptación social. Electronic Journal of Educational Psychology, 15, 6(2), 319-338. 